\title{
Are we ready for the World Cup? Uma avaliação ergonômica para analisar a qualidade de 51 sites relacionados à Copa do Mundo de 2014 e suas versões móveis
}

\author{
Diogo F. Trentini, Fernando T. Wasilewski, Lucas F. da Cunha, Isabela Gasparini \\ Departamento de Ciência da Computação \\ Universidade do Estado de Santa Catarina (UDESC) \\ Campus Universitário Prof. Avelino Marcante - 89.219-710 - Joinville - SC - Brasil \\ isabela.gasparini@udesc.br
}

\begin{abstract}
The World Cup is the world's most widely viewed sporting event. There are hundreds of websites that mention this event, therefore, an evaluation relating to the quality of user interaction is needed. This paper carried out an Ergonomic criteria evaluation of 51 websites related to 2014 World Cup event, and their mobile version, in order to evaluate their ergonomic quality and to find their ergonomic problems. This work aims to present the problems found in websites, their relation to the ergonomic criteria, and to compare the desktop website versus mobile/app version, besides it also wants to contribute for improving the user interaction with World Cup websites.
\end{abstract}

Resumo. A Copa do Mundo é o evento esportivo mais visto do mundo. Existem centenas de sites que mencionam este evento, desta forma, uma avaliação relacionada à qualidade da interação com o usuário se torna necessária. Este trabalho realizou uma avaliação ergonômica em 51 sites relacionados ao evento da Copa do Mundo de 2014, e sua versão móvel, a fim de avaliar a sua qualidade ergonômica e de encontrar os seus problemas ergonômicos. Este trabalho tem como objetivo apresentar os problemas encontrados em sites, sua relação com os critérios ergonômicos, e comparar a versão clássica do site com sua versão móvel/app, além de contribuir para melhorar a interação do usuário com os sites da Copa do Mundo.

\section{Introdução}

A Copa do Mundo é uma competição internacional de futebol disputado por equipes nacionais dos membros da Fédération Internationale de Football Association (FIFA), órgão mundial responsável pelo esporte e é o evento esportivo mais visto do mundo (WIKIPEDIA, 2013); cerca de 715,1 milhões de pessoas assistiram à partida final da Copa do Mundo da FIFA 2006, realizada na Alemanha (FIFA, 2013). A próxima Copa do Mundo será sediada pelo Brasil em 2014, e atualmente o foco está relacionado aos prazos para a construção e reformas na infraestrutura necessária para os jogos. Outro tema primordial para o sucesso da competição são as questões relacionadas à Tecnologia da Informação (TI). A disseminação de conhecimento e de informação são realmente importantes: será que os sites estão preparados para os diferentes usuários de todo o mundo? Estes sites são úteis e usáveis? Estas questões podem ser exploradas 
pelas avaliações ergonômicas e de usabilidade, relacionadas à qualidade de uso das interfaces.

Métodos de inspeção de usabilidade são métodos bem estabelecidos para a avaliação da interface de usuário (IU) de uma determinada aplicação, e diz respeito ao exame da interface realizado por um avaliador procurando por problemas de usabilidade. Estes métodos incluem as avaliações heurísticas, as diretrizes e recomendações de usabilidade, os percursos cognitivos, os percursos pluralísticos, as inspeções de conformidade e as ferramentas de inspeção (Scapin and Bastien, 1997). Estes métodos pertencem a uma classe informal de métodos de avaliação, pois a avaliação é realizada com base no conhecimento do avaliador ou com base no conhecimento armazenado no instrumento em si.

A usabilidade está relacionada à qualidade de uso dos sistemas, e depende de um acordo entre as características de sua interface e as características de seus usuários ao buscarem determinados objetivos em diferentes situações de uso. A ergonomia de sistemas está na origem da usabilidade, pois ela visa proporcionar eficácia, eficiência, saúde e bem-estar ao usuário, por meio da adaptação do trabalho ao ser humano (Cybis, Betiol e Faust 2010). Visando avaliar a qualidade ergonômica dos sites relacionados à Copa, este trabalho realiza uma inspeção de usabilidade através dos Critérios Ergonômicos em 51 sites relacionados à Copa do Mundo de 2014 e suas versões móveis. Este trabalho é uma continuação de Trentini et al (2013) e está estruturado como segue. A Seção 2 explica os conceitos da avaliação ergonômica. A seção 3 apresenta o processo de avaliação. A seção 4 mostra a análise e resultados da avaliação. A seção 5 destaca a conclusão do trabalho.

\section{Avaliação Ergonômica da Interface}

A Associação Internacional de Ergonomia define ergonomia como "a disciplina científica relacionada com a compreensão das interações entre os seres humanos e os outros elementos de um sistema, e a profissão que aplica os princípios teóricos, os dados e os métodos no design a fim de otimizar o bem estar humano e o desempenho geral do sistema" (IEA, 2014). Na área da Interação Humano Computador (IHC), a ergonomia está ligada à usabilidade de um sistema computacional. Existem vários métodos para avaliar a usabilidade de um determinado sistema, como a avaliação heurística, o percurso cognitivo, etc. (NIELSEN, MACK, 1994).

A avaliação heurística é um método informal de avaliação na qual, especialistas (por exemplo, designers de sistemas, engenheiros de software) analisam e avaliam a interface de usuário de uma aplicação (BASTIEN, SCAPIN, 1994). Diferentes trabalhos aplicaram este método para avaliar um sistema interativo, por exemplo, Kimura et. al (2012) avaliou os recursos de privacidade da rede social do Facebook aplicando três abordagens (inspeção do sistema, avaliação heurística e questionário com usuários reais); Scapin e Bastien (1997) apresentaram a concepção e avaliação de um conjunto de medidas chamado "critérios ergonômicos"; Piaia e Gasparini (2006) utilizam listas de verificação para a avaliação da usabilidade de um Ambiente de EAD; Scapin e Law (2007) realizaram uma revisão, um relatório e posteriormente um refinamento dos Métodos de Avaliação de Usabilidade. Em um estudo com cerca de 800 recomendações extraídas da literatura, eles as organizaram em grupos utilizando medidas normativas 
chamadas critérios que melhor descrevem a justificativa para usar tais recomendações. Os Critérios Ergonômicos foram projetados para estruturar o conhecimento da ergonomia e também para servir como uma técnica de inspeção ergonômica.

Para auxiliar a avaliação heurística, heurísticas são substituídas por um conjunto de oito critérios ergonômicos (BASTIEN, SCAPIN, 1993). Estes critérios ergonômicos têm, no mínimo, três vantagens (BODART, VANDERDONCKT, 1995): (i) são bem definidos; (ii) foram testados experimentalmente e validados; e (iii) podem ser ligados a regras ergonômicas úteis. Por isso, estes critérios ergonômicos tornaram-se muito importantes em tal análise, sendo uma ferramenta útil para pessoas que avaliam interfaces de usuário.

De acordo com Bastien e Scapin (BASTIEN, SCAPIN, 1993) e Scapin e Law (SCAPIN, LAW, 2010), os critérios ergonômicos são divididos em oito principais (primeiro nível) critérios, como segue: Condução, Carga de Trabalho do Usuário, Controle Explícito do Usuário, Adaptabilidade, Gestão de Erros, Homogeneidade/Consistência, Significado dos Códigos e Compatibilidade. Dentre esses, cinco critérios foram subdivididos outros subcritérios e critérios elementares.

O critério de Condução diz respeito aos meios de guiar, orientar e aconselhar o usuário enquanto ele interage com o sistema. Isso pode ser alcançado com a ajuda de mensagens, etiquetas, alertas, dicas, etc. É subdividido em quatro critérios: Presteza, Agrupamento/Distinção de Itens, Feedback Imediato e Legibilidade. A presteza está relacionada à forma de indicar o usuário de como executar certas ações. Agrupamento/Distinção de Itens refere-se à organização visual dos itens. Este critério é subdividido em dois critérios elementares: Agrupamento/Distinção de Itens por Localização, que diz respeito à localização de cada item, e Agrupamento/Distinção de Itens por Formato, na qual está relacionado aos recursos gráficos de cada item. Feedback Imediato está relacionado à resposta do sistema para toda ação do usuário. Legibilidade se refere às características da informação apresentada para o usuário, com a finalidade de ajudá-lo a entendê-la.

O critério Carga de Trabalho refere-se aos elementos da interface que reduz a percepção ou carga cognitiva do usuário. É subdividido em dois critérios: Brevidade e Densidade Informacional. Brevidade consiste em limitar o número de passos do usuário enquanto executa uma ação específica e limitar a carga de saída e entrada. Este subcritério é dividido em dois critérios elementares: Concisão, relacionado à percepção e carga cognitiva para entradas e saídas, e Ações Mínimas, que está relacionado ao número de ações para alcançar um objetivo específico. Densidade Informacional diz respeito à percepção e carga cognitiva do usuário relacionado a todo o conjunto de informações apresentado para ele.

Controle Explícito está relacionado ao controle que o usuário tem sobre as ações que podem ser realizadas dentro do sistema. Está subdividido em dois subcritérios: Ação Explícita do Usuário e Controle do Usuário. Ação Explícita do Usuário indica que o computador precisa processar as ações do usuário quando ele requisita e somente quando ele requisita. Controle do Usuário indica que o usuário precisa estar no controle do processamento do sistema. 
A Adaptabilidade refere-se à capacidade do sistema em mudar seu comportamento baseado nas necessidades do usuário. Está subdividido em dois critérios: Flexibilidade e Considerações sobre a Experiência do Usuário. Flexibilidade refere-se às formas disponíveis para o usuário personalizar a interface do sistema, em outras palavras, é a capacidade da interface do usuário de adaptar-se às necessidades particulares dos usuários. Experiência do Usuário está relacionada às considerações da experiência, ou inexperiência, dos usuários enquanto utilizam o sistema, isto é, está relacionada com os meios disponíveis para levar em conta o nível de experiência do usuário.

A Gestão de Erros refere-se aos meios que o sistema previne ou reduz erros, e se usuários estão aptos a recuperarem-se destes erros. Ele é subdividido em três critérios: Proteção de Erro, Qualidade das Mensagens de Erro e Correção de Erro. Proteção de Erro está relacionada aos meios de detectar e prevenir erros. Qualidade das Mensagens de Erro indica que a informação das mensagens de erro deve ser clara, exata e relevante para o usuário. Correção de Erro está relacionada aos meios disponíveis ao usuário para corrigir seus erros enquanto usa o sistema.

A Homogeneidade/Consistência diz respeito aos meios que o sistema mantém o mesmo design da interface em contextos similares ou se o sistema o mantém diferente em contextos distintos. Em outras palavras, o design da interface do sistema precisa seguir a mesma lógica, baseada em determinado contexto. O Significado dos Códigos refere-se ao relacionamento entre códigos e suas referências. Estes códigos precisam ser significativos para o usuário, ajudando-o a alcançar um melhor entendimento das suas funcionalidades. A Compatibilidade diz respeito à correspondência entre as características do usuário e as características da tarefa com a organização do sistema.

Os Critérios Ergonômicos são principalmente utilizados para avaliação e podem ser aplicados em diferentes estilos de interfaces interativas, por exemplo, as interfaces gráficas - GUIs (Graphical User Interfaces), Web e em realidade virtual (SCAPIN, LAW, 2007). O processo de avaliação dos sites da Copa do Mundo através dos Critérios Ergonômicos é apresentado na próxima seção.

\section{Processo de Avaliação}

O processo de avaliação teve início com a seleção de sites que tinham algum tipo de informação sobre a Copa do Mundo FIFA 2014 (sites de notícias, de andamento das obras de construção, guias turístico, e-commerce, etc.). Para isso, uma pesquisa exploratória na web foi realizada utilizando palavras-chave de pesquisa, (por exemplo, copa do mundo de 2014, Brasil, fifa, futebol) tanto em Português quanto em Inglês. Os resultados mais relevantes foram escolhidos em primeiro lugar, como sites de notícias, sites governamentais e sites institucionais. Depois disso, uma pesquisa mais profunda foi realizada para que outros tipos de sites com resultados menos relevantes pudessem ser selecionados (e.g. os blogs), e a última parte da pesquisa foi verificar se os sites selecionados tinham uma versão móvel ou um aplicativo dedicado (app) relacionado. $\mathrm{O}$ resultado gerado apresentou sessenta e nove sites, destes, dezenove também possuem uma versão móvel ou aplicativo dedicado.

Em seguida, um filtro foi aplicado para selecionar apenas os sites que têm uma seção sobre a Copa do Mundo ou aqueles que são completamente dedicados ao assunto. 
O resultado final, após o filtro, foi de cinquenta e um sites, destes, doze têm uma versão móvel e um site tem dois aplicativos dedicados (app), um para Android e outro para iOS (site Estadão).

A partir do resultado anterior, cada site foi avaliado de acordo com a sua qualidade ergonômica, com base nos critérios ergonômicos propostos por Bastien e Scapin (1993). Todo o processo de busca e de avaliação dos sites foi realizado no primeiro semestre de 2013, e foram avaliados ambos os sites em português e inglês. Os instrumentos (ou seja, os participantes, recursos de hardware/software e escopo) utilizados neste procedimento são explicados na seção 3.1., enquanto que o procedimento de avaliação é apresentado na seção 3.2.

\subsection{Instrumentos}

Como primeira etapa do estudo, foram definidos os participantes e os recursos. O grupo foi composto por dezenove alunos de graduação do curso de Ciência da Computação da Universidade do Estado de Santa Catarina (UDESC) inscritos na disciplina de IHC (Interação Humano-Computador). Os participantes foram divididos em grupos de duas ou três pessoas. Em média, cada grupo ficou responsável por avaliar 9 sites (incluindo suas versões móveis). Os alunos foram preparados para o processo de avaliação com os critérios ergonômicos, e um professor de IHC estava disponível ao longo de todo processo. Apesar dos alunos não serem especialistas em usabilidade, a experiência do professor neste tipo de avaliação auxiliou e conduziu os alunos no processo de avaliação realizado, de forma que as inspeções pudessem realmente encontrar a maioria dos problemas enfrentados pelos os usuários.

Cada indivíduo poderia usar sua própria máquina e os sites seriam testados em diferentes ambientes, desta forma, nenhum padrão foi estabelecido em relação aos recursos de software e hardware, porém, como todos participantes puderam utilizar os recursos da universidade para o desenvolvimento do trabalho, os principais recursos utilizados para a avaliação da versão clássica dos sites foram os sistemas operacionais Windows 7 e Ubuntu 12.xx; as resoluções de tela de 1360x768 e 1920x1080, e os navegadores Chrome 26.0 e Firefox 20.0.1. Os principais recursos utilizados para avaliar a versão móvel do site foram os sistemas operacionais Android 4.x e iOS 6.x; as resoluções de tela de 320x480, 640x480 e 720x1280, e os navegadores Chrome 26.0 e Safari 6.x. O âmbito da avaliação era encontrar sites relacionados (ou dedicados) aos sites da Copa do Mundo 2014. Os sites que foram avaliados na pesquisa são apresentados na Tabela 1.

Tabela 1. Sites avaliados relacionados à Copa de 2014

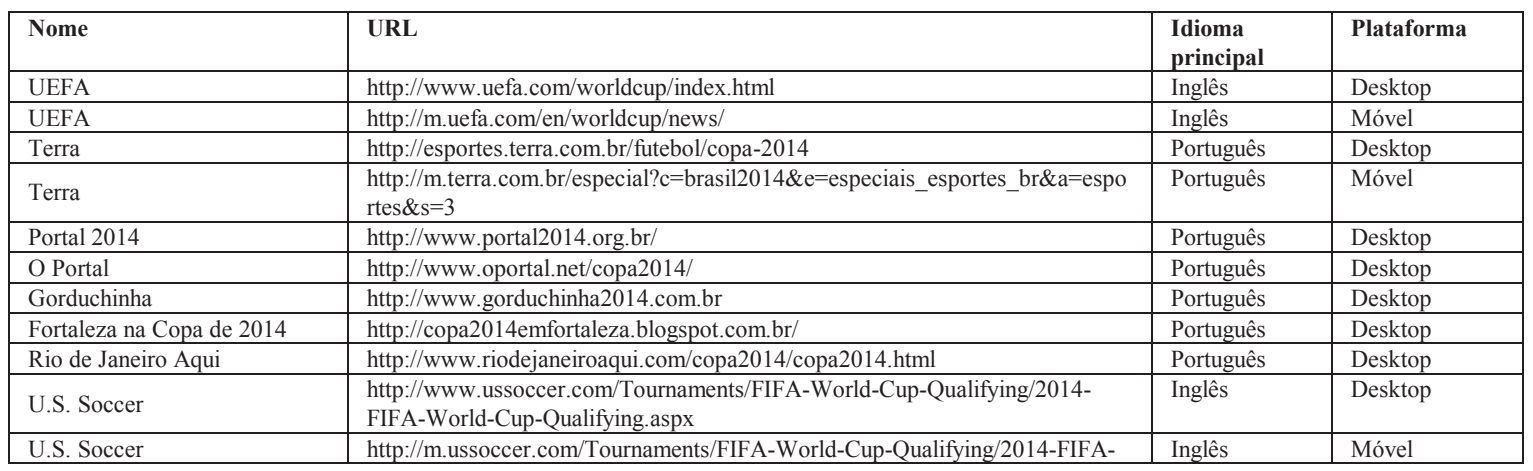




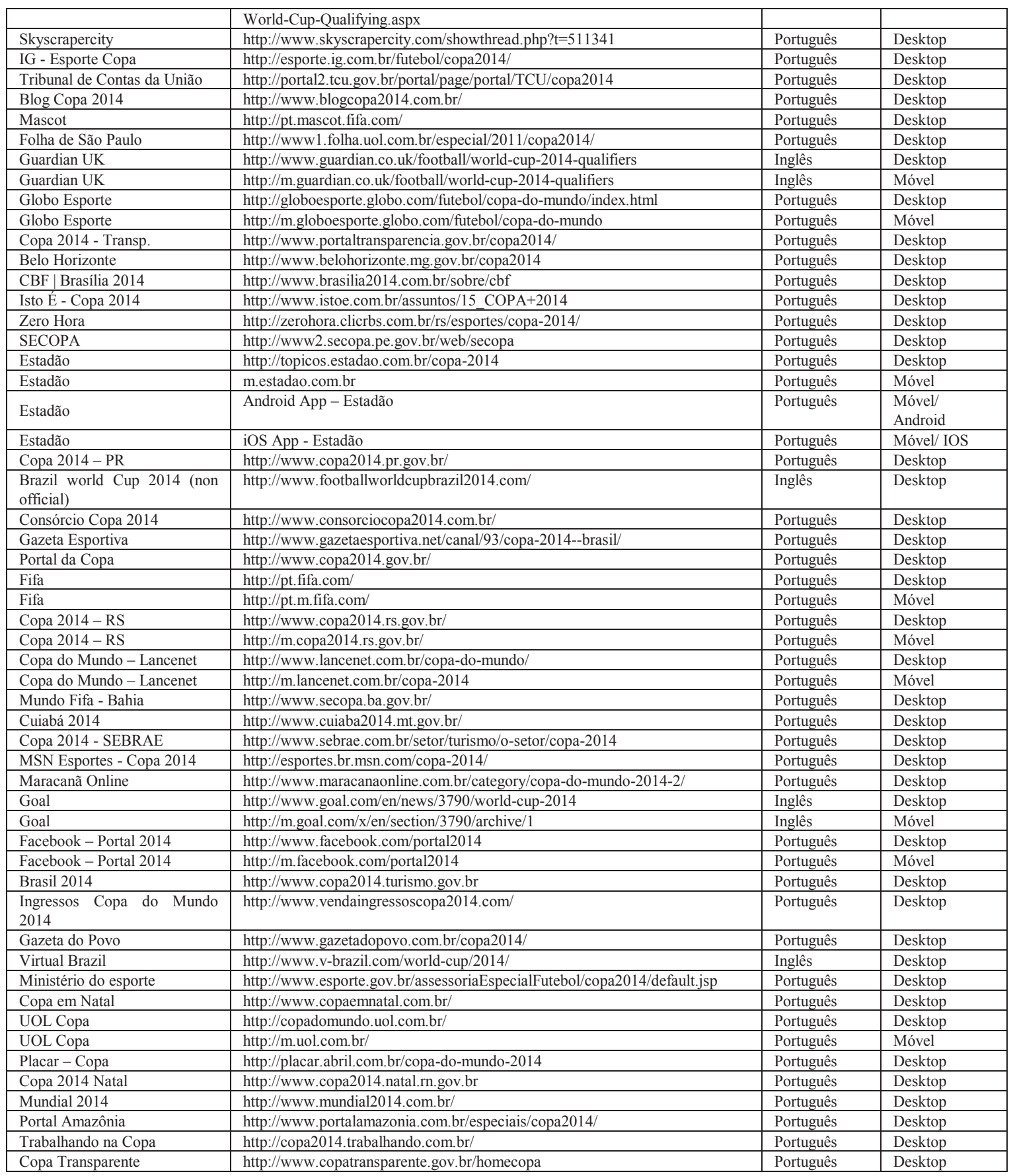

\subsection{Procedimentos}

A avaliação foi feita em todas as porções dos sites que eram relacionadas à Copa do Mundo. Os participantes tiveram que explorar todas as unidades da interface, desta forma eles (a) realizaram cada passo que o usuário tem que fazer para alcançar um objetivo (por exemplo, ler uma notícia, postar um comentário, cadastrar-se no site, etc.) e (b) analisaram todos os elementos do site (por exemplo, tabelas, botões, dicas de ferramentas, campos de entrada, etc.). Durante esses passos, se o critério era dividido em subcritérios, foram avaliados apenas os subcritérios, se o site não conseguiu (não satisfez) um desses critérios/subcritérios ele receberia um "não" no critério/subcritério, se ele obteve sucesso (satisfizeram os critérios) ele receberia um "sim" e se os critérios 
não poderiam ser aplicados ele receberia um "NA" (Não Aplicável). Para todos os principais critérios com subcritérios, se um dos subcritérios tem um "NÃO", então o critério principal recebe um "NÃO" também. Para os sites que foram totalmente dedicados à Copa do Mundo, todo o site foi avaliado, se o site tinha uma seção sobre a Copa do Mundo, só esta seção foi avaliada.

Algumas das tarefas realizadas durante a avaliação dos sites foram: navegar por todas as páginas do site; analisar a disposição dos elementos de cada página (a fim de verificar a densidade informacional, legibilidade, etc.); submeter todos os formulários disponíveis (para verificação de critérios relacionados à gestão de erros); clicar em todos os botões e links existentes; acessar links inexistentes (para verificar a existência de páginas de erros); analisar legendas e símbolos; verificar a presença de funcionalidades de adaptabilidade (como ajustar o tamanho da fonte); analisar a ausência de funcionalidades importantes para o usuário; entre outras.

Nas figuras a seguir é possível verificar alguns erros comuns que foram observados durante a avaliação, como por exemplo, mensagens de erros sem clareza, assim, o usuário se torna confuso sobre o que causou esse erro e como se recuperar deste erro a partir das informações recebidas (Figura 1a e 1b). O usuário não tem controle total sobre a sua ação, por exemplo, ao enviar um comentário ele não é capaz de editá-lo ou apagá-lo (Figura 2). Alguns sites também não têm agrupamentos com distinção clara, especialmente em relação ao seu formato, como visto por exemplo na Figura 3, onde a tabela poderia apresentar separadores de linha, indicando com maior clareza a divisão dos itens.

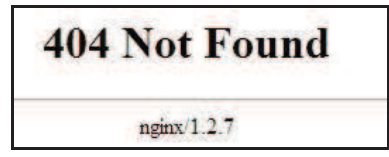

(a) SkyscraperCity

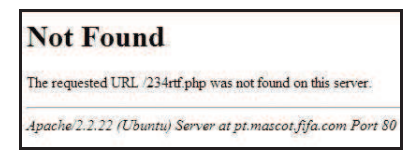

(b) Mascot Fifa

Figura 1. Qualidade das mensagens de erros - mensagens que não ajudam o usuário a identificar o que está acontecendo e como sair dessa situação

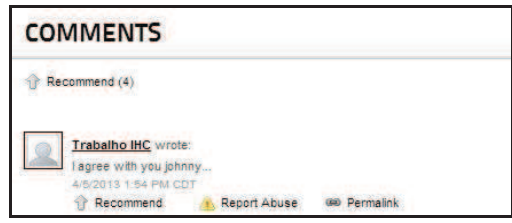

Figura 2. Controle do usuário - O usuário não pode editar ou apagar seu comentário depois de postá-lo no site U.S. Soccer's na versão desktop (www.ussoccer.com)

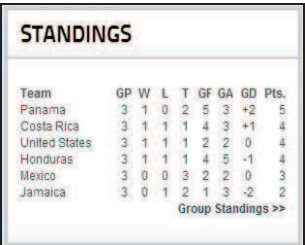

Figura 3. Agrupamento e distinção dos itens por formato - A tabela não possui nenhuma separação em os diferentes itens no site U.S. Soccer na versão desktop (www.ussoccer.com) 
O site O Portal - Copa 2014 apresenta falta de homogeneidade no menu principal, apresentando anúncios no meio do menu, e diferentes tipos de fonte e conteúdo em um mesmo menu, conforme apresentado na Figura 4.

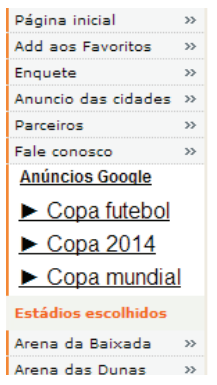

Figura 4. Propaganda e diferentes formatos e tipos de conteúdo no site o Portal versão desktop (http://www.oportal.net/copa2014/)

\section{Análises e Resultados}

Os resultados obtidos a partir do processo de avaliação foram inseridos em uma tabela, que teve como objetivo gerar os gráficos apresentados na seção 4.1 e 4.2. Na seção 4.1 é feita uma análise com base em cada um dos critérios ergonômicos. Na seção 4.2, os websites são comparados com a sua versão móvel ou o seu aplicativo dedicado.

\subsection{Por critérios e subcritérios}

Esta seção apresenta os resultados de todos os websites em relação a cada um dos critérios ergonômicos. Para verificar se um determinado critério estava em conformidade (o website estava satisfazendo este critério) todos os subcritérios deveriam estar em conformidade também, sendo assim, alguns dos critérios apresentaram uma conformidade menor do que seus subcritérios em si. $\mathrm{O}$ critério de Adaptabilidade foi o menos satisfeito pelos websites (ou seja, o que apresentou maiores não conformidades), com apenas 6,15\%. Isto se deve ao fato de que a maioria dos websites não faz nenhum tipo de diferenciação entre um usuário experiente e um inexperiente (Experiência do Usuário) e também não permite ao usuário alterar a interface de acordo com as suas necessidades (Flexibilidade). Isto é particularmente ruim visto que estes websites lidam com um público heterogêneo, advindo de diversos países e diferentes culturas.

Outro problema ergonômico está relacionado ao critério de Gestão de Erros, com apenas $27,69 \%$ de conformidade: o problema mais comum encontrado foi que o usuário não podia editar ou apagar um comentário depois da sua submissão se o mesmo cometeu algum erro (Correção de Erros), além disso, os sites não preveniam o usuário de entrar com informações erradas em alguns dos campos de entrada (Proteção de Erros) e a qualidade das mensagens não estavam claras de acordo com o que aconteceu, como links quebrados ou campos com entradas erradas (Qualidade das Mensagens de Erro).

Apesar da boa avaliação dos subcritérios, o critério de Condução foi satisfeito por $23,08 \%$ dos sites. Isto porque foi difícil para o site satisfazer todos os subcritérios do critério principal. Os sites geralmente satisfizeram 3 a 4 subcritérios de Condução, indicando que o critério foi satisfeito em um determinado nível. Este critério é 
importante especialmente para o usuário novato na aplicação (neste caso, sites), porque pode prevenir os dois grandes problemas na Web, o sentimento de 'perdido no hiperespaço' e a 'sobrecarga cognitiva'. Uma boa condução facilita o aprendizado e a utilização de um sistema permitindo ao usuário: saber em qualquer momento a sua localização no sistema numa determinada sequência de interações, ou durante a realização de uma tarefa; saber quais são as possíveis ações como também as suas consequências; e obter informação adicional (sob demanda), e a facilidade de aprendizado e de uso advindo de uma boa condução permitem ao usuário obter um melhor desempenho e reduzir o número de erros durante a interação (Scapin e Bastien 1997). A Figura 5 mostra a porcentagem dos sites (versão desktop e móvel) que satisfizeram cada subcritério.

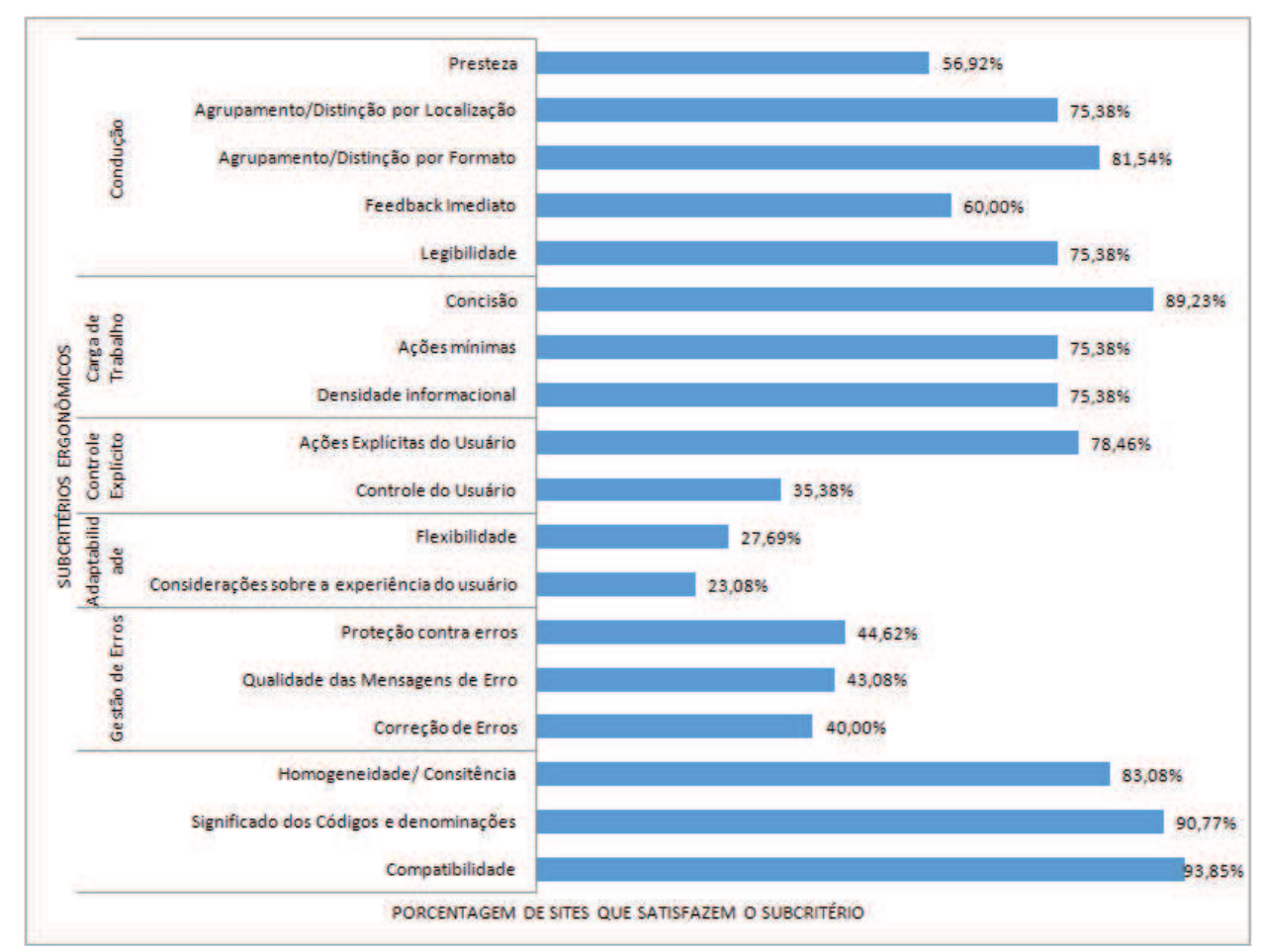

Figura 5. A Porcentagem de conformidade para cada subcritério de cada site (versão desktop e móvel)

\subsection{Comparação da Versão Clássica e Móvel}

As características das versões móveis são geralmente herdadas das suas respectivas versões desktop. Isto explica porque as versões móveis possuem quase os mesmos problemas ergonômicos que estão presentes nas suas versões clássicas. Na Figura 6 é apresentada a comparação entre as versões clássica (chamada aqui de desktop) e móvel, enquanto a Figura 7 apresenta uma comparação da versão desktop e móvel relacionada a cada subcritério dos Critérios Ergonômicos. Como pode ser visto, as versões móveis geralmente satisfizeram um número menor de critérios comparado à versão desktop. Um dos grandes problemas está na distinção da avaliação de cada versão. Este problema surge pois os designers e desenvolvedores web não levam em consideração a consistência do conteúdo e as tarefas suportadas por cada aplicação. Além disso, devese levar em consideração que as recomendações e diretrizes para desenvolver um site 
clássico estão consolidadas enquanto que as diretrizes e recomendações para o desenvolvimento de sites e aplicativos móveis ainda estão sendo estudadas.

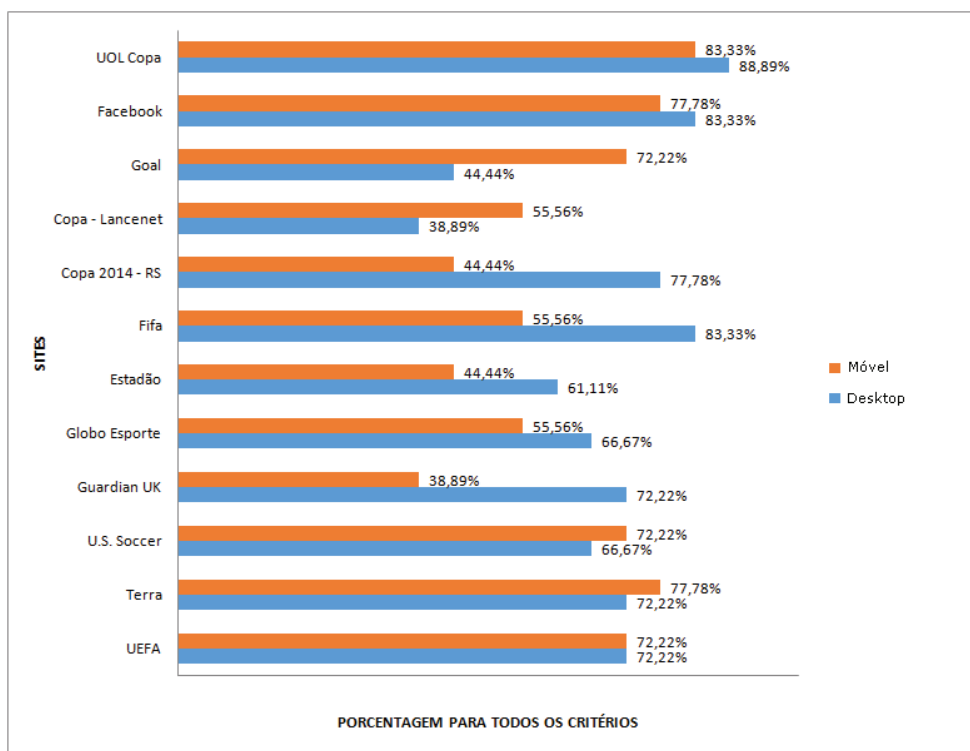

Figura 6. Porcentagem dos critérios atendidos para cada site

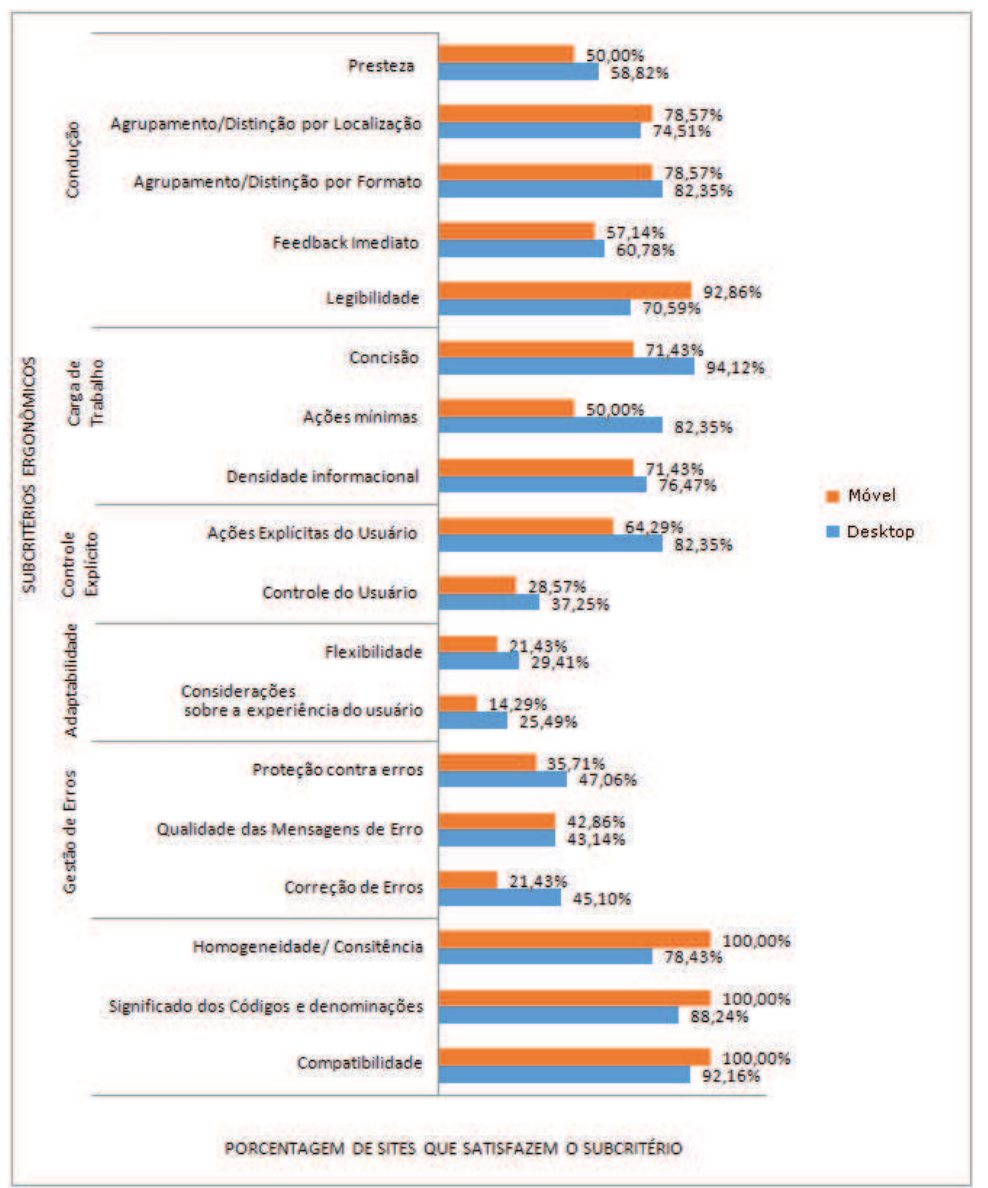

Figura 7. Porcentagem de sites que satisfazem cada subcritério 
Apesar das versões desktop terem se saído melhor que as versões móveis na maior parte das avaliações, é importante analisar em quais critérios o contrário ocorreu. As versões móveis obtiveram um melhor desempenho em critérios como Legibilidade, indicando que, provavelmente, os desenvolvedores para dispositivos móveis tendem a se preocupar mais com as limitações do dispositivo (como, por exemplo, tamanho da tela) e como as informações são dispostas ao usuário. É importante que sites e aplicativos móveis sejam de fácil entendimento até mesmo por causa do escopo onde estão inseridos (por exemplo, uma pessoa utiliza seu celular em diversos momentos e lugares distintos, enquanto o desktop é, muitas vezes, restrito a momentos e lugares específicos). Isso também pode ser válido para outros critérios como Homogeneidade, Significado dos códigos e denominações e Compatibilidade, onde sites móveis tiveram maior conformidade em relação às suas versões desktop.

Apesar de o levantamento inicial apresentar dezenas de sites relacionados à Copa do Mundo de 2014, a maioria deles não possui uma versão móvel (ou uma aplicação dedicada para uma plataforma móvel). Sendo assim, a comparação entre a versão clássica e móvel foi limitada a 12 sites.

\section{Conclusão}

Com a proximidade da Copa do Mundo no Brasil em 2014, a população está preocupada com as pendências em relação à estrutura para a Copa, em diversos segmentos da sociedade. Na área de TI essa preocupação também pode ser percebida, visto que diversos sistemas e sites devem estar funcionais, disponíveis e usáveis para auxiliar o público que deseja desde acesso à informação, realizar compras e reservas, buscar e analisar consultas, etc.

Este trabalho realizou a avaliação ergonômica de 51 sites relacionados à Copa do Mundo de 2014, disponíveis no primeiro semestre de 2013. O processo de avaliação baseou-se nos critérios ergonômicos propostos por Scapin e Bastien (1993) visto a facilidade de verificação dos critérios ergonômicos, do grau de experiência dos avaliadores e do tempo disponível para a avaliação. As tarefas e conteúdo de cada site foram analisados, com diferentes recursos (e.g. resolução, sistema operacional, navegador, smartphone, desktop). Com este trabalho, percebeu-se a grande importância das conformidades dos critérios ergonômicos por parte desses sistemas. Apesar de algumas não conformidades não causarem total desconforto por parte do usuário, a ausência de outros acaba impactando na experiência de uso do usuário.

O objetivo deste trabalho não estava em examinar qual site foi o melhor avaliado, mas discutir como os diferentes problemas podem ser identificados com base numa avaliação da qualidade com base nos critérios ergonômicos. Este trabalho mostrou a importância da realização de uma avaliação ergonômica e identificou potenciais problemas que os usuários podem enfrentar ao usar sites da Copa do Mundo de 2014.

Obviamente, este estudo não responde a todos os problemas de usabilidade destacados na literatura, mas identifica uma direção dos problemas encontrados por um método de inspeção. Este trabalho abordou de uma forma geral os diferentes problemas que podem ser enfrentados por diferentes tipos de usuários, porém, outros métodos de avaliação podem ser aplicados especificamente a usuários novatos, usuários culturalmente distintos, usuários com necessidades especiais, etc., para melhor entender 
os diferentes problemas de usabilidade relacionados com os diferentes grupos de usuários.

\section{Referências}

Bastien, J. C. e Scapin, D. L., 1993. Ergonomic criteria for the evaluation of humancomputer interfaces. Institut National de Recherche en Informatique et en Automatique, Technical report $\mathrm{N}^{\circ}$ 156, Rocquencourt France, pp. 1-41.

Bastien, J. C. e Scapin, D. L., 1994. Evaluating a user interface with ergonomic criteria. Rocquencourt, France, pp. 7.

Bodart, F. e Vanderdonckt, J. 1995. Using ergonomic rules for evaluation by linguistic ergonomic criteria. Advances in Human Factors/Ergonomics, vol. 20, pp. 367-372.

Cybis, W; Beitol, A; Faust, R. 2010. Ergonomia e Usabilidade - Conhecimentos, Métodos e Aplicações, $2^{\mathrm{a}}$. edição, Novatec.

FIFA - The Official Website of the FIFA World Cup ${ }^{\text {TM }}$. 2013. Disponível em http://www.fifa.com/worldcup/index.html

International Ergonomics Association (IEA). 2014. Disponível em http://www.iea.cc/

Kimura, M. H., Mantau, M. J., Kemczinski, A., Gasparini, I., Berkenbrock, C. D. M. 2012. Usability evaluation of Facebook's privacy features: comparison of experts and users. Proceedings of the IADIS International Conference WWW/INTERNET 2012 (ICWI2012), Madri, p. 290 - 297.

Nielsen, J. e Mack, R. L., 1994. Usability Inspection Methods. Wiley, New York, USA.

Piaia, J., Gasparini, I. O Uso de Listas de Verificação para Avaliação da Usabilidade de um Ambiente de EAD na Web. III Simpósio Brasileiro de Sistemas de Informação (SBSI), 2006, Curitiba.

Scapin, D.L. e Bastien, J.C. 1997. Ergonomic criteria for evaluating the ergonomic quality of interactive systems. Behaviour \& Information Technology, 16:4-5, 220231.

Scapin, D. e Law, E. 2007. R3UEMs: Review, Report and Refine Usability Evaluation Methods. The 3rd COST294-MAUSE International Workshop. Atenas, Grécia. Disponível em http://www.cost294.org/

Trentini, D. F., Wasilewski, F. T., Cunha, L. F., Gasparini, I. Are world cup 2014 websites prepared?! An ergonomic evaluation of 51 websites and their mobile versions. In: IADIS International Conference WWW/INTERNET 2013 (ICWI 2013), 2013, Fort Worth. p. 303-308.

Wikipedia FIFA World Cup. 2013. Disponível em http://en.wikipedia.org/wiki/FIFA_World_Cup, France, pp. 1-41. 